\title{
SYPHILIS OF THE LUNG
}

BY

\section{M. LIBRACH}

Syphilis of the lung is considered to be very uncommon. Osler (1912) found only twelve cases in 2,500 autopsies, and Babcock (1911) discovered only one in 6,000 . However, if one considers the autopsies of syphilis alone, the frequency of lung involvement naturally increases. Thus, Netchaew found 22 cases among 437 syphilitics, and Stolper saw five cases in 61 syphilitics (both are quoted by Versé, 1931), whereas Carrera (1920) discovered twelve instances in 152 cases. The average incidence, according to Tchertkoff and Berwick (1941), seems to be 8 per cent. of all luetics brought to autopsy. Karshner (1910) says that pulmonary syphilis is twice as frequent amongst males as amongst females, the peak of the age incidence being in the early thirties. Most cases occur five or more years after primary infection, though Dieulafoy (1889) put them at 10 to 11 years later, i.e. later than late syphilitic visceral involvement.

Post-mortem reports of cases occur frequently in the literature (De Jong (1936), Versé (1931), Prévôt (1935), Dienst (1932), Kokawa (1906), Hammer (1931), Karshner (1920), etc.-all quoted by Tchertkoff and Berwick, 1941), but reports of this condition in living patients seem to be rare. Thus Tchertkoff and Berwick (1941) report one case in a coloured woman; De Navasquez (1942) cites another in a soldier aged 57 years; Romanus (1941) describes a further example in a 42-year-old female ; Pearson and De Navasquez (1938) report two cases; Lyons and others (1942) mention one case, and Kulchar and Windholz (1947) describe four cases, of whom one died and another was treated successfully with penicillin. Wilson (1946) discusses with post-mortem findings a case of bronchopneumonia in a Mexican male aged 69 years, in whom a post-mortem revealed spirochaetes in the fibrotic lung areas.

More recent articles have discussed the clinical recognition of late-acquired cases without post- mortem confirmation. Thus Loubeyre and Grangaud (1948) report a case in a North African male patient aged 30 years with a putrid lung abscess and bronchiectasis whom they claim was cured by bismuth and arsenic. Findlay and others (1949) describe the case of a gumma of lung in a Negro aged 39 years, treated with penicillin and Lugol's iodine, and later by lobectomy.

\section{Case Record}

A.F.P., a bachelor aged 49 years, a greengrocer, first attended a chest clinic on 24 Sept., 1947, with a six months' history of lassitude, tiredness, and loss of weight and appetite. He had brought up a moderate amount of mucopurulent sputum. During this time he had been treated for "nerves". A chest $x$ ray on that date showed extensive mottling at the right apex with discrete heavy shadows at the bases and "peaking" of both leaves of the diaphragm (Fig. 1). A sputum examination, also 24 Sept., 1947, was reported as positive for acid-fast bacilli. There was no family history of tuberculosis, and past history was not noteworthy, except that in January 1945 he had been an in-patient in hospital for treatment of "duodenal ulcer "- - the history then was nausea, vomiting, and abdominal pain for 10 days. Unfortunately I have been unable to trace the results of any investigation done at that time, including a barium-meal examination, which the patient volunteered was performed. (The symptoms, however, suggest a "gastric" crisis.) He was told to go home and rest, while awaiting admission to a sanatorium. He was admitted to Ilford Isolation Hospital on 30 June, 1948, when he repeated his previous history of loss of weight, strength, and appetite. He also complained of "tightness and fulness of the chest". He had been slightly deaf since the 1914-18 war.

Examination showed a thin, phthinoid, edentulous patient. His temperature in the mouth was $99^{\circ} \mathrm{F}$. pulse-rate 72 per minute, and respirations 20 per minute. The heart sounds were normal, but there was some impairment of resonance with diminished breath sounds at the right apex. An E.S.R. was $12 \mathrm{~mm}$. in 1 hour (Westergren method, at room temperature). A chest radiograph revealed a fibroid appearance at the right 


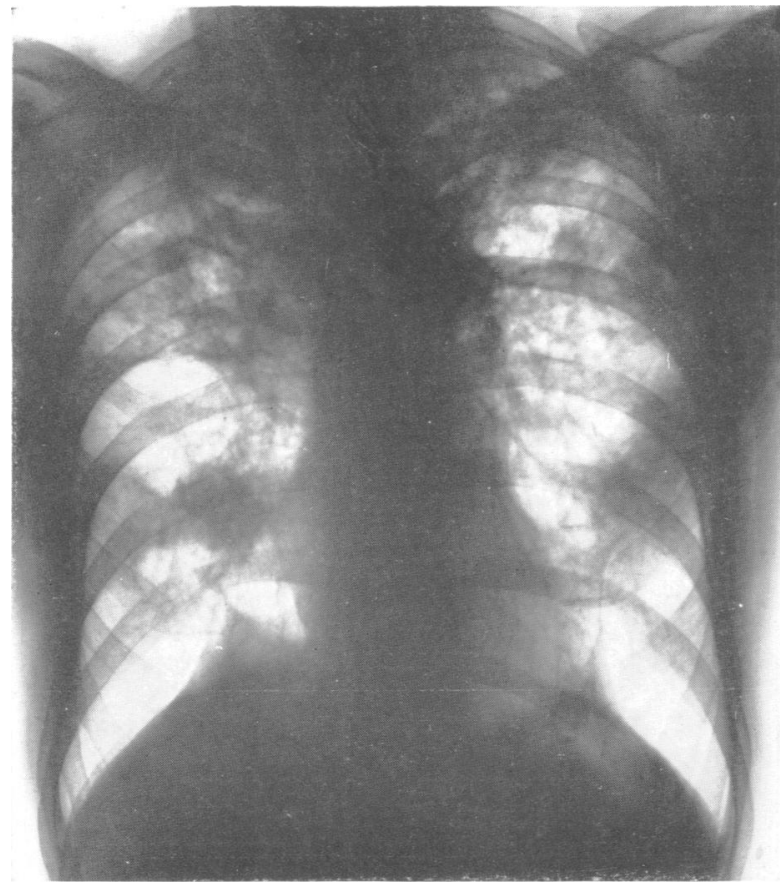

Fig. 1.-Radiograph of chest, Sept. 24, 1947, showing extensive disease in both lungs before admission to hospital.

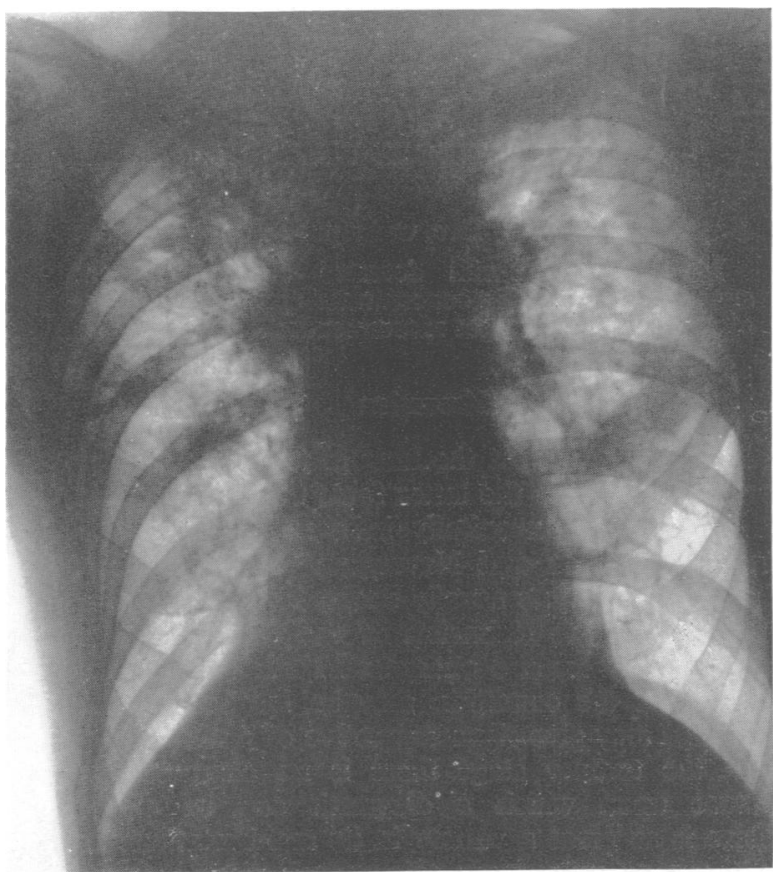

FIG. 2.-Radiograph of chest on admission to hospital, June 30,1948 , still showing extensive bilateral fibrotic disease, predominantly apical in distribution. lung apex, hard shadows in both mid zones, exaggerated hilar shadows, and ill-defined mottling in the left upper and mid zones (Fig. 2). Successive sputum examinations for acid-fast bacilli on six occasions were negative. Progress was equivocal. The pulse-rate varied from 70 to 80 per minute and was of regular rhythm. A slight evening rise of temperature to $99^{\circ} \mathrm{F}$. occurred during the first four days in hospital, but subsequent readings were normal.

On 11 Sept. he complained of pains in the knees, which kept him awake at night, but no gross joint signs were elicited. On 1 Oct. he had a sudden attack, consisting of pain in the neck and shoulders, giddiness, vomiting, and double vision. He complained that the ward seemed to be spinning round him and that people were "cut in half". He was fully conscious but was flushed, the pulse rate being regular at 60 per minute. The blood pressure in the arms was 14580 , the temperature was $99.4^{\circ} \mathrm{F}$. and the respiratory rate 20 . Examination of the nervous system revealed the following findings: Both pupils showed no reaction to light, but reacted to accommodation. The right was larger than the left, but both were regular and circular. The visual fields and retinae were normal. There was no nystagmus. He was slightly deaf in both ears but the drums were intact. No other cranial nerves showed any abnormality. All deep reflexes were exaggerated in both arms and legs. The plantar reflexes were extensor. He was hypoaesthetic to pin-prick over the whole body, but especially in both legs, where muscle sense was also diminished, but joint sense was present. Other forms of sensation were not impaired. Two days later he felt better, the pulse rate rising to 80 per minute. Subsequent questioning elicited a history of a penile chancre, contracted on war service in 1916, which had been treated with mercury and salvarsan for six weeks.

The following investigations were performed at the time :

Blood Wassermann Reaction: strongly positive.

Lumbar Puncture: Cerebrospinal fluid deeply xanthochromic and not under pressure. No evidence of spinal block apparent.

Examination of cerebrospinal fluid: Red cells 3,000. White cells 15 (Polymorphs 60 per cent. Protein $120 \mathrm{mg}$. per cent. Chlorides $730 \mathrm{mg}$. per cent.).

Wassermann Reaction : Strongly positive.

Lange Curve : 5555543210

Culture : Sterile.

Blood Examination: Hb 76 per cent. Red cells $3,600,000$. White cells 5,800 (polymorphs 64 per cent. lymphocytes 30 per cent. monocytes 6 per cent.).

$X$ ray of skull (P.A. and Lateral) : Normal.

Urine: Normal.

He was transferred on 20 Oct. (after 4 months in this hospital) to a venereal diseases department. There the diagnosis of neurosyphilis was confirmed, and he was given a course of 85 injections of 40,000 units of penicillin 2-hourly followed by a course of arsenic and bismuth. An E.S.R. at this time was $20 \mathrm{~mm}$. in 1 hour (Westergren) and packed red cell volume 47 per cent. 


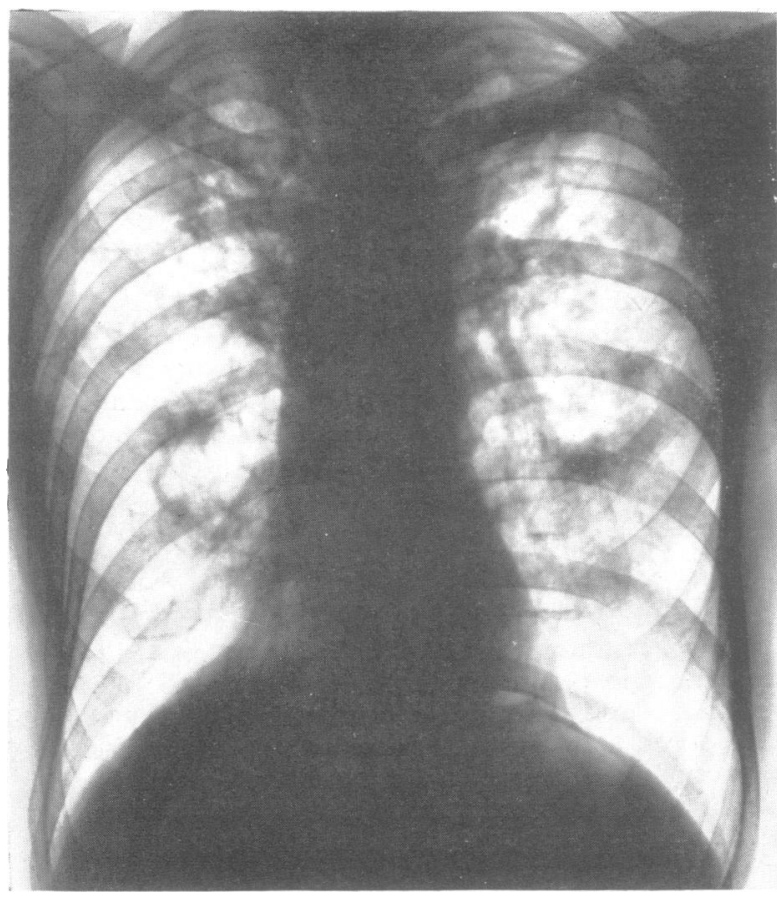

FIG. 3.-Radiograph of chest, Jan. 12, 1949, after a course of penicillin, bismuth, and arsenic, showing shrinkage of the lung opacities.

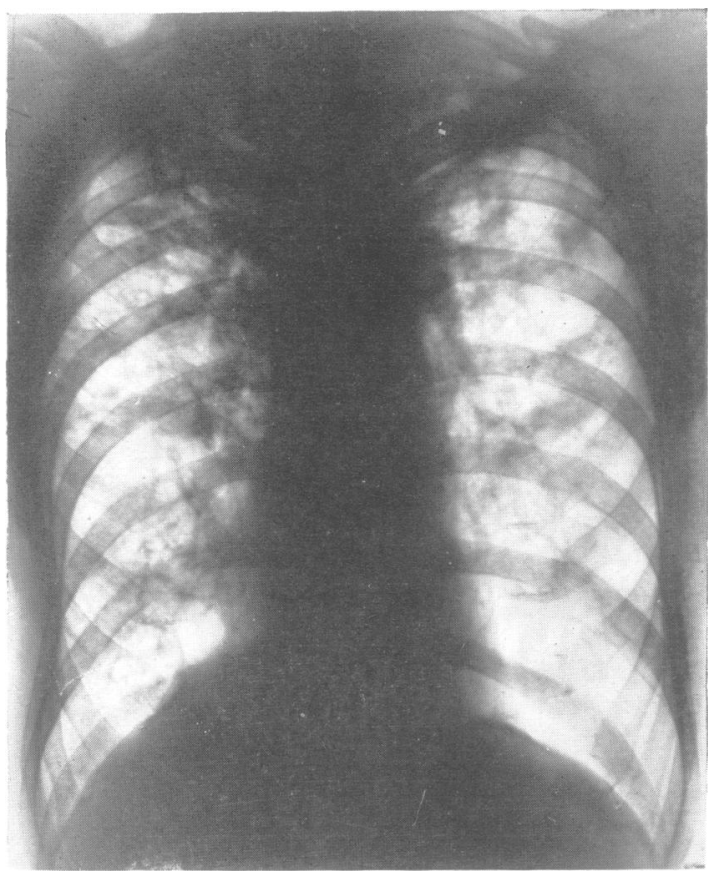

FiG. 4.-Radiograph taken more than one year after admission to hospital, October, 1949. There is no aortic involvement and though irregular apical opacities are still present, the remainder of the lung fields are clear.
On discharge from this latter hospital he defaulted from attendance, because he was unable to undertake the journey to the clinic. On 12 Jan., 1949, arrangements were made for him to attend the chest clinic again and there his general condition was found to be poor. He was very short of breath, and a chest radiograph (Fig. 3) showed some shrinkage of the lung opacities as compared with the original film.

On 13 Aug. he again attended the clinic. His weight was $8 \mathrm{st} .4 \mathrm{lb} .8 \mathrm{oz}$. (almost the same as when discharged from hospital). He had a little cough and sputumunfortunately it was not tested for $B$. tuberculosis at this time. His $x$ ray showed little change and was consistent with chronic upper-zone fibrosis.

In October 1949 I had a letter from his doctor (Dr. Fife) stating that his general condition had improved, that he was now enjoying life and going to watch speedway racing. His Wassermann reaction was still positive.

On 29 Dec. (over a year later) I saw him again and was surprised at the remarkable clinical improvement. Though his weight remained steady at $8 \mathrm{st}$. $5 \mathrm{lb}$. with clothes on, his general demeanour was bright and cheerful. He was not breathless, and said that he only became so on over-exertion. He was apyrexial, and his pulse rate was normal. He said he had little or no sputum. There was no finger clubbing, but he was still kyphotic.

Over the past year he had had two further courses of Bismostab-10 $\times 1 \mathrm{ml}$. His Wassermann reaction, though still positive, was less strongly so than before. An $x$ ray of the chest (Fig. 4) taken in October 1949 showed that the lung fields were considerably clearer than the previous year. The mass in the right mid zone had disappeared, but there were still irregular opacities at both apices, much less in extent than in the original film. There was no obvious radiological aortic involvement.

A sputum test on 29 Dec. was reported on as follows :

No acid-fast bacilli detected after fluorescent examination of highly concentrated sputum. Guineapig inoculation was not recommended.

\section{Discussion}

Syphilis may affect the lung in the secondary or tertiary stages-in the latter form the " pneumonia alba" of the congenitally infected infant is well known. Pearson and Navasquez (1938) state that the secondary type usually occurs in the form of a bronchitis due to extension of the ulceration that affects the fauces and pharynx. Funk (1920) 'considers that the condition may be localized to an apex and may give signs suggestive of phthisis.

In the tertiary stage there is no characteristic picture upon which a diagnosis can be made. There is as great a variety in its manifestations as in those of pulmonary tuberculosis itself. Often there is a long history of disease with a multiplicity of clinical signs. At other times, however, the lesion is discovered accidentally in the course of routine screening in a patient, whose main complaint 
is due to disease of some other organ (Hartung and Freedman, 1932).

The lesion is said to affect most often the middle and lower lobes, but this may well be because, when the apices are left clear, it is more likely to be differentiated from tuberculous infection. A number of cases in which the upper lobes have been affected exclusively have been recorded (Raybaud and Jouve, 1934 ; Stoichitza and Cretzu, 1935). Late syphilis of lung, perhaps more than any form of visceral involvement, tends to stimulate other diseases and consequently escapes clinical recognition (Kulchar and Windholz, 1947).

According to Pearson and De Navasquez (1938), the criteria, upon which a clinical diagnosis may be made, can be summarized thus :

(1) An anomalous history of pulmonary disease, often with haemoptysis, cough, loss of weight, and fever, of brief duration or extending over a period of years.

(2) Exclusion of common causes such as new growth, and tuberculosis, the latter by repeated failure to find tubercle bacilli in the sputum.

(3) The presence of a history of syphilis and of associated syphilitic lesions in other organs and of positive serum reactions such as Wassermann and Kahn.

(4) The effect of antiluetic therapy.

(5) The radiographic appearances particularly in association with response to treatment.

Hartung and Freedman (1932) add two further points :

(6) Demonstration of the Treponema pallidum in sputum or pleural fluid, etc., or by direct lung puncture (Munson, 1944; quoted by Wilson, 1946).

(7) Anatomical confirmation where possible.

In many cases it is impossible at present to make more than a tentative diagnosis on clinical grounds alone.

If the present case is compared with the above criteria, one finds an anomalous history of cough and loss of weight, with signs of meningovascular involvement confirmed by positive Wassermann reaction in the blood and cerebrospinal fluid. The radiographic appearances might well be either syphilitic or tuberculous. Kulchar and Windholz (1947) state that pulmonary syphilis is frequently asymptomatic, or presents symptoms so trivial as to pass unnoticed by both patient and physician ; physical signs are likewise often absent or minimal, so that the presence of the lesion is often only detected by radiography. Pearson and De Navasquez (1938) classify the common radiographic appearances thus :

(1) Infiltration, lobar or patchy in distribution, involving the whole or part of one or more lobes.
(2) Opacities, roughly oval in shape, most often involving the lower lobes, and single or multiple.

(3) Generalized accentuation of the bronchial and vascular shadows, often with a beaded appearance, radiating from the lung roots.

(4) One lobe, or the whole of one side of the chest, may be opaque with deviation of the medial stinum due to fibrosis, pulmonary collapse, or pleural effusion.

Have we adequately excluded tuberculosis? The sputum, scanty in amount, was negative on six successive occasions, and again more than a year after discharge from hospital. The original positive report might reasonably be expected to be confirmed two years later. No apparent deterioration, radiological or otherwise, could be detected on admission, or again one year later. One might also expect cavitation to be found in disease of this duration. Heaf and Rusby (1948) state that too much emphasis should not be placed upon even a series of negative results, if other features are suggestive of a tuberculous lesion. In this case, however, the lesions might equally be considered syphilitic especially in the presence of the positive blood Wassermann test.

Kulchar and Windholz (1947) state that dyspnoea of varying degree and commonly induced or accentuated by exertion, and usually described as a sense of pressure or tightness in the chest, is present in these cases. Again, according to these authors, and to Hartung and Freedman (1932), it appears that the symptoms and clinical course of late pulmonary syphilis are milder than those of pulmonary tuberculosis. Both these points are seen in the case here described. These writers also mention that the untreated disease in the lungs remains stationary or is only slowly progressive. The response to treatment is in almost all instances dramatic and gratifying in those cases diagnosed early. On the other hand, chronic fibrotic cases are notoriously resistant to treatment ; this would appear to be only partially borne out by the present case, in whom quite definite improvement occurred after penicillin therapy as well as treatment with arsenic and bismuth.

The effect of antiluetic therapy on pulmonary tuberculosis is discussed by Hoffmann and Adams (1944). These authors conclude that it is without effect in this disease, as do Lecaplain (1923) and Skavlem (1928). For obvious reasons Hoffmann and Adams (1944) do not mention the effect of peniciilin on tuberculosis, but it is now well known that this has no effect on the progress of the disease. They do mention the fact that tuberculosis may cause a false positive reaction for syphilis. Out of 239 tests done in 69 patients, only two were positive, and one of these was followed by three negative 
results, while the other died before confirmation could be obtained. In the present case, the fact that there are definite signs of meningovascular involvement must be held as confirming the presence of syphilis.

Kulchar and Windholz (1947) consider radiography of the chest to be by far the most important factor in the detection of the disease and in the judging of the effect of the therapeutic test upon it. While the results of therapy are by no means infallible, this still remains the only method of confirming the diagnosis during life, until methods of demonstrating the spirochaete are improved. By this yardstick the present case may be considered to show some improvement, because the latest radiograph (Fig. 4) demonstrates a reduction in the apical opacities, disappearance of the right midzonal mass, and a general clearing of the lung fields. However, it behoves one to be cautious of the effect of antiluetic therapy on pulmonary syphilis. As Findlay and others (1949) state, many of the reputed lesions which have shown dramatic $x$-ray response to medical treatment have never been proven or examined pathologically, and this certainly applies to the case here recorded.

In conclusion, it might be of interest to discuss in brief the conditions which determine the onset of the pulmonary lesions in a given case. Pearson and De Navasquez (1938) hold that the earliest changes are interstitial, i.e. they are confined to the vessels, and peribronchial and alveolar tissues. The respiratory passage is excluded as a portal of entry because of the late involvement, if any, of the bronchial epithelium. The fan-shaped distribution of the lesion suggests an initial spread from hilum to periphery, thus supporting a preceding mediastinal infection such as aortitis or aneurysm. They think that aortic involvement is invariably present in pulmonary syphilis. Vivoli (1935) noted aortic involvement in 75 per cent. of 25 cases. Symmers (1916) found aortic changes in 55.7 per cent. of 314 cases and lung involvement in 10.5 per cent. of these, while Carrera (1920) described twelve cases all showing cardio-aortic changes. No clinical or radiological signs of aortitis were apparent in the case described above, though, of course, latent changes might be present.

\section{Summary}

A case of meningovascular syphilis with possible pulmonary involvement in a man aged 49 years is described, together with a discussion on the aetiology, pathology, and treatment of the condition. The difficulty in differentiating the lung involvement from pulmonary tuberculosis is stressed.
I should like to thank Dr. J. H. Weir (former Medical Officer of Health, Ilford) for his most helpful criticism of this paper, and for permission to publish it. I am grateful to Dr. Thompson (Chest Physician, Romford) for his help and for permission to use his radiographs ; to Dr. Elliott (Venereologist, Oldchurch County Hospital, Romford) for the clinical findings while the case was under his care ; to my colleague, Dr. G. L. Brown, for his helpful advice and assistance; and to Dr. Atkinson of the Department of Pathology, Oldchurch Hospital, for the pathological findings.

\section{REFERENCES}

Babcock, R. H. (1911). Interst. med. J., 18, 85.

Carrera, J. L. (1920). Amer. J. Syph., 4, 1.

Dienst, C. (1932). Röntgenpraxis, 4, 703.

Dieulafoy, A. (1889). Gaz. hebd. Méd. Chir., 26, 285.

Findlay, C. W., Lehman, W. J., and Rottenberg, L. A. (1949). Ann. Surg., 129, 274.

Funk, E. H. (1920). Amer. Rev. Tuberc., 3, 754.

Hammer, H. (1931). Röntgenpraxis, 3, 301.

Hartung, A., and Freedman, J. (1932). J. Amer. med. Ass., 98, 1969.

Heaf, F., and Rusby, N. L. (1948). “ "Recent Advances in Respiratory Tuberculosis," 4th ed., p. 74. Churchill, London.

Hoffmann, R., and Adams, G. (1944). Amer. Rev. Tuberc., 50, 85 .

Howard, C. P. (1924). Amer. J. Syph., 8, 1.

De Jong, S. I. (1926). Ann. Anat. path. med-chir., 3, 193.

Karshner, R. G., and Karshner, C. F. (1920). Ann. Med., Hagerstown, 1, 371.

Kokawa, I. (1906). Arch. Derm. Syph., Wien, 78, 319.

Kulchar, G. V., and Windholz, F. (1947). Amer. J. Syph., 31, 166.

Lecaplain, J. (1923). J. Amer. med. Ass., 81, 256.

Loubeyre, J., and Grangaud (1948). Bull. Soc. méd. Hôp. Paris, 64, 331.

Lyons, C. G., Brogan, A. J., and Sawyer, J. G. (1942). Amer. J. Roentgenol., 47, 877.

Munson, L. (1944). Med. Bull. Veterans'Adm., Wash., $20,305$.

De Navasquez, S. (1942). J. Path. Bact., 54, 315.

Netschaew, A., and Eward, B. (1926). Arch. Derm. Syph., Wien, 150, 213.

Osler, W. (1912). "The Principles and Practice of Medicine," 8th ed. Appleton, New York.

Pearson, R. S. B., and De Navasquez, S. (1938). British Journal of Venereal Diseases, 14, 243.

Prévôt, R. (1935). Röntgenpraxis, 7, 686.

Raybaud, A., and Jouve, A. (1934). Arch. méd-chir. Appar. resp., 9, 337.

Romanus, T. (1941). Acta derm.-venereol., Stockh., 22, 565 .

Skavlem, J. H. (1928). Amer. J. Syph., 12, 355.

Stoichitza, N. N., and Cretzu, V. (1935). Arch. méd.chir. Appar. resp., 10, 1.

Stolper, P. (1896). "Beiträge zur Syphilis visceralis, Magen-, Lungen- und Herz-syphilis." Fischer, Cassel.

Symmers, D. (1916). J. Amer. med. Ass., 66, 1457.

Tchertkoff, I. G., and Berwick, P. (1941). Quart. Bull. Sea View Hosp., 7, 324.

Versé, M. (1931). Henke and Lubarsch's " Handbuch der Speziellen Pathologischen Anatomie und Histologie", vol. 3, pt. 3, p. 164.

Vivoli, D. (1935). Prensa méd. argent., 22, 1569, 1627, $1669,1736,1770,1811,1875$.

Wilson, J. M. (1946). Ann. intern. Med., 25, 134. 